\title{
RESEARCH
}

\section{Efficacy of intensive multitherapy for patients with type 2 diabetes mellitus: a randomized controlled trial}

\author{
Julie Ménard, Hélène Payette, Jean-Patrice Baillargeon, Pierre Maheux, Serge Lepage, \\ Daniel Tessier, Jean-Luc Ardilouze
}

Early release, published at www.cmaj.ca on Nov. 17, 2005. An abridged version of this article is available in the Dec. 6, 2005, issue of CMAJ.

\section{ABSTRACT \\ Background: National guidelines for managing diabetes set standards for care. We sought to determine whether a 1-year intensive multitherapy program resulted in greater goal at- tainment than usual care among patients with poorly con- trolled type 2 diabetes mellitus.}

Methods: We identified patients with poorly controlled type 2 diabetes receiving outpatient care in the community or at our hospital. Patients $30-70$ years of age with a hemoglobin $A_{1 c}$ concentration of $8 \%$ or greater were randomly assigned to receive intensive multitherapy $\left(n=3^{6}\right)$ or usual care $\left(n=3^{6}\right)$.

Results: The average hemoglobin $A_{1 c}$ concentration at entry was $9.1 \%$ (standard deviation [SD] $1 \%$ ) in the intensive therapy group and $9.3 \%$ (SD $1 \%$ ) in the usual therapy group. By 12 months, a higher proportion of patients in the intensive therapy group than in the control group had achieved Canadian Diabetes Association (CDA) goals for hemoglobin $A_{1 c}$ concentrations (goal $\leq 7.0 \%: 35 \%$ v. $8 \%$ ), diastolic blood pressure (goal < $80 \mathrm{~mm} \mathrm{Hg:} 64 \%$ v. $37 \%$ ), low-density lipoprotein cholesterol (LDL-C) levels (goal $<2.5 \mathrm{mmol} / \mathrm{L}: 53 \%$ v. $20 \%$ ) and triglyceride levels (goal $<1.5 \mathrm{mmol} / \mathrm{L}: 44 \% \mathrm{v}$. $14 \%$ ). There were no significant differences between the 2 groups in attaining the targets for fasting plasma glucose levels, systolic blood pressure or total cholesterol:highdensity lipoprotein cholesterol ratio. None of the patients reached all CDA treatment goals. By 18 months, differences in goal attainment were no longer evident between the 2 groups, except for LDL-C levels. Quality of life, as measured by a specific questionnaire, increased in both groups, with a greater increase in the intensive therapy group (13\% [SD $10 \%$ ] v. $6 \%$ [SD 13\%], $p<0.003$ ).

Interpretation: Intensive multitherapy for patients with poorly controlled type 2 diabetes is successful in helping patients meet most of the goals set by a national diabetes association. However, 6 months after intensive therapy stopped and patients returned to usual care, the benefits had vanished.

Cite this article as CMAJ 2005;I73(I2). DOI:I0.I503/cmaj.050054
$\mathrm{R}$ educing plasma glucose levels, ${ }^{1,2}$ blood pressure ${ }^{3-5}$ or lipoprotein levels ${ }^{6-8}$ delays the development or progression of complications in patients with type 2 diabetes mellitus. This has prompted calls for intensive multitherapy treatment. ${ }^{9,10}$ To date, only 4 studies of multitherapy management have been published, all of which showed major beneficial effects on long-term outcome. ${ }^{11-14}$ The Canadian Diabetes Association (CDA) ${ }^{15}$ and the American Diabetes Association (ADA ${ }^{16}$ both publish guidelines on a regular basis and recommend that people with type 2 diabetes receive tailored, stepwise and proactive therapy including lifestyle intervention and pharmacologic treatment from a multidisciplinary team. However, neither set of guidelines has been evaluated by a prospective study.

We hypothesized that a I2-month, intensive multitherapy program provided by a multidisciplinary team would reduce fasting plasma glucose levels, hemoglobin $\mathrm{A}_{\mathrm{rc}}$ concentrations, blood pressure and lipoprotein levels to the CDArecommended goals, that these benefits would be maintained beyond the intervention period (i.e., at least 6 months later), and that the intervention would improve patient quality of life. To assess the effects and feasibility of intensive multitherapy in the vast population of patients who are commonly seen by family practitioners and endocrinologists, we chose subjects in whom the disease was poorly controlled and who, although at very high risk of micro- and macrovascular events, ${ }^{2,4,6}$ were without significant complications.

\section{Methods}

Patients with type 2 diabetes mellitus (I985 World Health Organization criteria) and receiving any therapy regimen, between 30 and 70 years of age and with hemoglobin $\mathrm{A}_{\mathrm{rc}}$ concentrations of $8 \%$ or greater were eligible to participate in the study. We excluded patients with hypoglycemia unawareness, severe or uncontrolled cardiovascular disease (defined as a cardiovascular event within the last year), dyspnea higher than class $\mathrm{II},{ }^{17}$ proteinuria greater than $300 \mathrm{mg} /$ day, proliferative retinopathy (defined as growth of new blood vessels on the retina and posterior surface of the vitreous), chronic foot ul- 
cers or wounds, or psychiatric disease or cognitive impairment interfering with treatment compliance. We also excluded patients who were unable to perform the exercise program or detect sensation with the use of a Io-g monofilament.

Recruitment lasted I3 months. All patients who participated in educational sessions at the Diabetes Daycare Centre at our hospital were contacted by mail. Patients first received a letter explaining they would be contacted by the study coordinator to participate in a study. Other patients contacted us directly, after endocrinologists and primary care physicians in the Sherbrooke area were canvassed and newspapers advertisements were published. Prospective participants were first screened for exclusion criteria by telephone, and the design and aims of the study were explained. Thereafter, the screening visit, which included an exercise tolerance test,${ }^{17}$ finalized recruitment.

The study was designed as a I2-month controlled trial with a 6-month post-intervention assessment. Using a blocked randomization $(n=4)$ stratified by hemoglobin $\mathrm{A}_{\mathrm{rc}}$ value ( $<10 \%$ and $\geq 10 \%$ ), patients were assigned by an independent person using a computer program to receive intensive multitherapy or usual care. At the end of the I2-month intervention period, patients who had received intensive multitherapy resumed usual care. A final assessment was performed at 18 months.

Patients in the intensive multitherapy group each had monthly visits to the Clinical Research Centre of the Centre Hospitalier Universitaire de Sherbrooke, where they received individualized education regarding diet, physical exercise and information on managing diabetes, hypertension and hyperlipidemia. Between each visit, patients monitored their blood glucose levels at least twice daily and received at least 2 phone calls for information on test results, therapy adjustments and motivation.

The dietary intervention was based on the Canadian Nutrition Recommendations: $:^{15}$ carbohydrates contributed 50\%$55 \%$ to the total daily energy intake, total fats less than $30 \%$, and saturated fatty acids less than $10 \%$. Dietary compliance was assessed at baseline and at 6 and 12 months using a food record of 3 nonconsecutive days (one weekend day and 2 weekdays). The Candat software ${ }^{18}$ was used to calculate intake of energy and nutrients.

The individualized home-based physical exercise program included use of an exercise bicycle (Weider Electronic Ergocycle, St. Jerome, Qué.) and elastic exercise bands (Hygienic Corporation, Akron, Ohio). Each session was monitored with a heart rate monitor (Polar Electro, Woodbury, NY) and included 4 phases: warm-up, cardiovascular, resistance and cool-down stretching. The frequency ( $3-5$ times/week), duration (45-55 minutes) and intensity $(50 \%-80 \%$ of the maximum heart rate) of the sessions were adapted to the patient's baseline exercise tolerance test ${ }^{19}$ and progressively increased. Exercise tolerance tests were repeated at 12 months. Physical exercise was assessed using a standardized questionnaire ${ }^{20}$ at baseline and at 6 and 12 months. The weekly exercise volume was calculated as metabolic equivalent task (MET) according to the type of activity $\times$ frequency $\times$ duration..$^{21}$

Pharmacologic therapy was introduced or increased at 3 months in patients who had not reached the treatment goals with lifestyle interventions and their current medications. Glyburide was started or increased to a maximum of $20 \mathrm{mg}$ daily, metformin to a maximum of $2550 \mathrm{mg}$ daily and $\alpha$-glucosidase inhibitors to a maximum of $300 \mathrm{mg}$ daily. If hemoglobin $\mathrm{A}_{\mathrm{rc}}$ concentrations remained at $7 \%$ or greater after the maximum oral antihypoglycemic treatment was reached, bedtime intermediate-acting insulin was added. Then, as with those patients already taking insulin, the type of insulin (intermediate, premixed preparations, regular or lispro), number of injections ( $\mathrm{I}-4)$ and dosages were adjusted. For hypertension, fosinopril (an angiotensin-converting enzyme inhibitor) was used as first-line therapy, and amlodipine (a calcium-channel antagonist), hydrochlorothiazide (a diuretic), atenolol (a $\beta$ blocker), irbesartan (an angiotensin-II receptor antagonist) and doxazosin (an $\alpha$-blocker) were added and increased as recommended. ${ }^{15}$ Fibrates (bezafibrate) or statins (pravastatin) or a combination of both was used as indicated. ${ }^{15}$ ASA ( $80 \mathrm{mg}$ daily) was given as a secondary prevention strategy. The optimal dosages and number of pills were increased according to therapeutic goals, secondary effects and patient agreement. Information about medications and compliance was obtained from detailed patient interviews at baseline and at 6, I2 and I8 months. To simplify comparisons and calculations, given that other types of antihyperglycemic, antihypertensive and lipidlowering drugs could be given to the patients in the control group, each drug dosage was calculated as a percentage of the maximum dosage according to the 1998 Compendium of Pharmaceuticals and Specialties.

Patients in the control group remained under the care of their family physician or endocrinologist or both. For ethical reasons, they were given general health and diabetes-related advice at each laboratory visit. Patients in the control group visited the the Clinical Research Centre of the Centre Hospitalier Universitaire de Sherbrooke at baseline and at 6, I2 and I8 months. Laboratory test results were given to the patients by telephone. Clinical (weight, body mass index, blood pressure) and biochemical data, as well as recommended guidelines for therapy, were mailed to their physicians.

The outcome variables were fasting plasma glucose levels, hemoglobin $\mathrm{A}_{\mathrm{rc}}$ concentrations, blood pressure, serum lipoprotein levels and quality of life. Fasting plasma glucose levels, hemoglobin $\mathrm{A}_{\mathrm{rc}}$ concentrations, blood pressure and serum lipoprotein levels were measured after a I2-hour, overnight fast at baseline and at 6, I2 and I8 months. Weight and height were measured, and body mass index $\left(\mathrm{kg} / \mathrm{m}^{2}\right)$ was calculated. Fasting plasma glucose levels were measured using a glucose oxidaze method. Cholesterol, high-density lipoprotein cholesterol, and triglyceride levels were measured using a colorimetric process (Johnson \& Johnson Ortho-Clinical Diagnostics, Rochester, NY). Low-density lipoprotein cholesterol levels were calculated with the Friedewald formula. Hemoglobin $\mathrm{A}_{\mathrm{rc}}$ concentrations were measured by high-performance liquid chromatography (Bio-Rad VARIANT, Hercules, Calif.). The nondiabetic reference range in our laboratory is $4.0 \%-6.0 \%$. Systolic and diastolic blood pressure were calculated as the average of 3 readings taken at 2-minute intervals using the arm with the highest blood pressure, with the patient in a sitting position after 5 minutes of 
rest. A mercury-column sphygmomanometer was used, with cuff-size adjustment based on arm circumference.

The frequency and severity of hypoglycemic episodes or any other adverse events were recorded at each visit. Hypoglycemia was defined as any glucose measurement of $3.5 \mathrm{mmol} / \mathrm{L}$ or less, and an episode was recorded as "severe" if the assistance of another person was required.

To address quality of life, a specific questionnaire was developed and validated. Satisfaction, impact and diabetesrelated worry were scored according to a 5-point Likert scale ranging from I (very satisfied, no impact, no worry) to 5 (very dissatisfied, very impacted, very worried). To make the results easier to understand, scores were converted to a roo-point scale, roo reflecting highest quality of life. A detailed description of the instrument and the validation process will be presented in a separate paper. The questionnaire was selfadministered at baseline and at 6 and $\mathrm{I} 2$ months.
Statistical analyses were carried out according to the intention-to-treat principle. Baseline characteristics of the 2 groups were compared using an unpaired Student's $t$ test, $\chi^{2}$ or Fisher's exact test. Outcome variables measured at baseline and at 6 and 12 months were compared using repeated-measurements analysis of covariance with the baseline values used as covariates. ${ }^{22}$ The change in outcome variables between $\mathrm{I} 2$ and 18 months and between baseline and 18 months was tested with paired Student's $t$ test or Wilcoxon test. An unpaired Student's $t$ test or the Mann-Whitney test was used to test group differences at I8 months. Changes in proportion in the same group were assessed with the McNemar test. All $p$ values were computed for 2 -tailed tests at an $\alpha$ level of 0.05 .

The study was approved by the ethics committee of the Centre Hospitalier Universitaire de Sherbrooke, and participants signed a written informed consent in accordance with the Helsinki declaration.

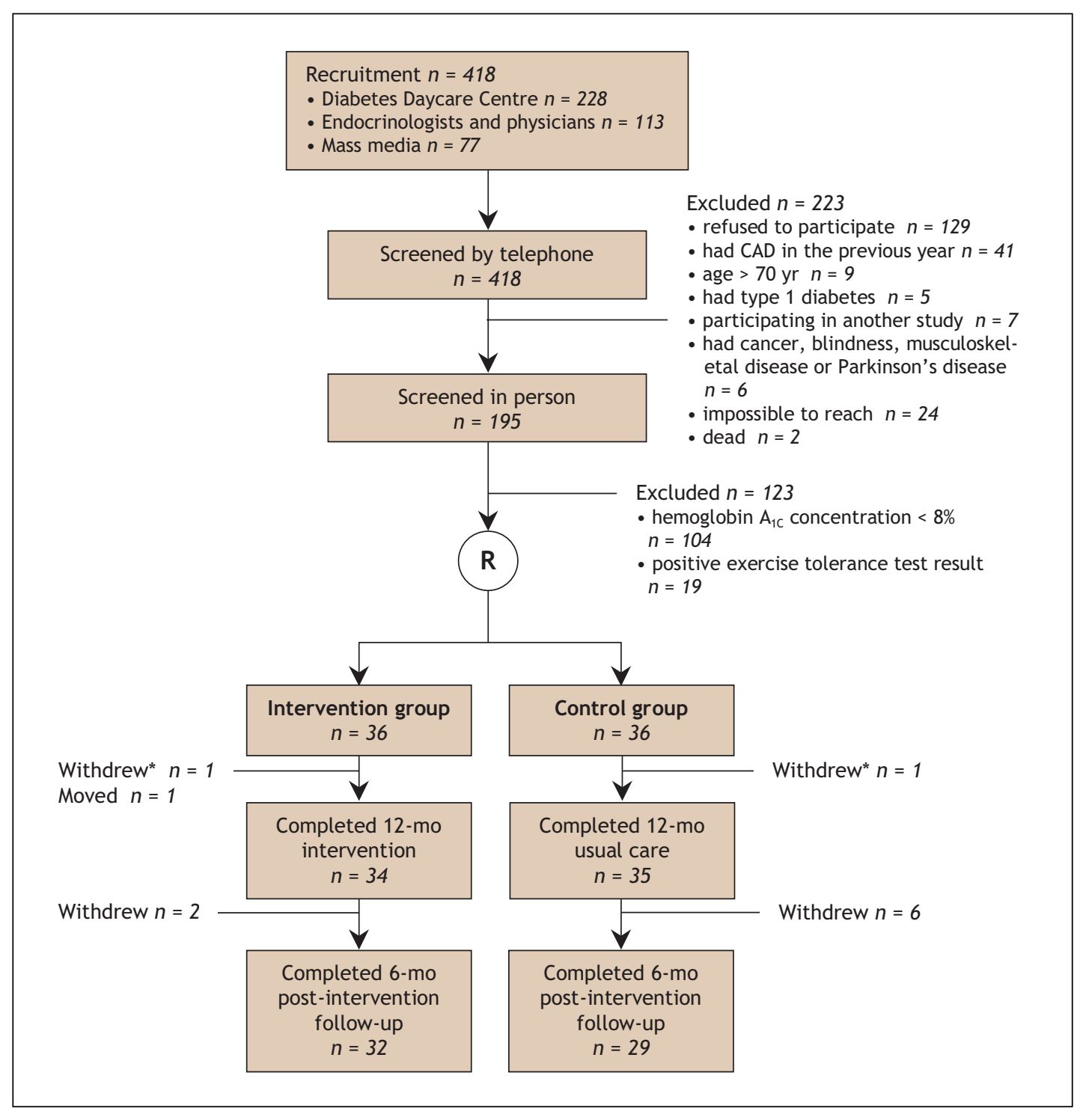

Fig. 1: Flow of participants through the study. CAD = coronary artery disease. ${ }^{*}$ Did not attend the 12 -month visit but attended all other visits. 


\section{Results}

\section{Baseline}

Of 418 patients initially recruited, 36 patients were randomly assigned into each treatment arm (Fig. I). There was no significant difference between the 2 groups in age, sex, duration of diabetes, smoking or antihyperglycemic medications (Table I). The number of complications was similar in both groups. A total of 24 patients in the intervention group and $3 \mathrm{I}$ in the control group, or $76 \%$ of all study subjects, had participated in a 4-day diabetes education program in the 12 months before entry in the study, and $70 \%$ ( $n=25$ in each group) were under the care of endocrinologists in addition to their general practitioner. Glycemic indices showed poor control in all subjects (Table $\mathrm{I}$ ). A total of 7 study participants $(5$ in the intervention group v. 2 in the control group) were normotensive, $13(8 \mathrm{v} .5)$ were at target for systolic blood pressure, and I9 (II v. 8) were at target for diastolic blood pressure; 23 in the intervention group and $2 \mathrm{I}$ in the control group were taking antihypertensive medications. No patient had a normal lipid profile, but I7 (8 in the intervention group v. 9 in the control group) were at treatment target for low-density lipoprotein cholesterol levels, 5 (I v. 4) for total cholesterol:high-density lipoprotein cholesterol ratio and I2 (IO V. 2) for triglyceride levels; one-third (I2 v. 15) were taking lipid-lowering agents. Quality-of-life scores were identical in the $\mathbf{2}$ groups (Table 2 ).

\section{At 12 months}

At 12 months, a higher proportion of patients in the intervention group had achieved CDA goals for hemoglobin $\mathrm{A}_{\mathrm{rc}}$ concentrations, diastolic blood pressure, and low-density lipoprotein cholesterol and triglyceride levels than in the control group (Table 3). There were no significant differences between the groups in goal attainment for fasting plasma glucose levels, systolic blood pressure or total cholesterol:highdensity lipoprotein cholesterol ratio. Results remained similar (data not shown) when we performed an analysis that included the 3 subjects who withdrew during the first 12 months ( 2 in the intervention group and $\mathrm{I}$ in the control group).

Although no patients achieved all of the targets, improvements were significantly greater in the intervention group compared with the control group with respect to fasting plasma glucose levels, hemoglobin $\mathrm{A}_{\mathrm{Ic}}$ concentrations, systolic blood pressure and triglyceride levels (Fig. 2, Table 4). Significant differences were already observed at 6 months (data not shown). There was no significant increase in weight in either study group.

Energy and fat intake (total fat, saturated fatty acids and cholesterol) decreased significantly between baseline and I2 months in the intervention group (Table 2). In both groups, the proportion of subjects who met the recommendations for carbohydrate, total fat and saturated fatty acid intake was identical: $56 \%, 28 \%$ and $37 \%$, respectively.

Exercise volume improved between baseline and 12 months in the intervention group, and the mean time during the tolerance test increased to over 6 minutes in this group.
Twenty subjects had 3 or more exercise sessions per week, and those who exercised less often than 3 sessions per week were compliant with the prescribed duration and intensity of sessions (9I.2\% and $100 \%$, respectively). Exercise volume did not change in the control group.

At the end of $\mathrm{I} 2$ months (Table 4, Table 5), $68 \%$ of patients in the intervention group were taking insulin compared with $40 \%$ in the control group $(p<0.05)$, and the dosage of insulin

Table 1: Baseline characteristics of patients with poorly controlled type 2 diabetes mellitus receiving intensive multitherapy (intervention group) and usual care (control group)

\begin{tabular}{|c|c|c|}
\hline Characteristic & $\begin{array}{l}\text { Intervention group } \\
\qquad n=36\end{array}$ & $\begin{array}{c}\text { Control group } \\
\qquad n=36\end{array}$ \\
\hline Age, mean (SD), yr & $53.7(7.5)$ & $55.9(8.6)$ \\
\hline Sex, men/women & $27 / 9$ & $22 / 14$ \\
\hline $\begin{array}{l}\text { Duration of diabetes, } \\
\text { mean (SD), yr }\end{array}$ & $10.6(6.7)$ & $10.0(7.7)$ \\
\hline Smoker, no. & 5 & 6 \\
\hline \multicolumn{3}{|l|}{$\begin{array}{l}\text { Biochemical variables, } \\
\text { mean (SD) }\end{array}$} \\
\hline Weight, kg & $93.5(20.1)$ & $88.5(18.3)$ \\
\hline $\mathrm{BMI}, \mathrm{kg} / \mathrm{m}^{2}$ & $32.9(5.5)$ & $32.6(5.7)$ \\
\hline Systolic BP, mm Hg & $144(20)$ & $143(17)$ \\
\hline Diastolic BP, mm Hg & $85(11)$ & $86(10)$ \\
\hline FPG, mmol/L & $10.8(3.5)$ & $10.8(3.0)$ \\
\hline $\mathrm{HbA}_{1 c}, \%$ & $9.1(1.0)$ & $9.3(1.0)$ \\
\hline LDL-C, mmol/L & $3.26(1.03)$ & $2.98(1.18)$ \\
\hline C:HDL-C ratio & $6.38(2.14)$ & $6.03(1.96)$ \\
\hline Triglycerides, mmol/L & $3.08(3.09)$ & $3.68(2.48)$ \\
\hline \multicolumn{3}{|l|}{ Medications, no. } \\
\hline \multicolumn{3}{|c|}{ Antihyperglycemic medications } \\
\hline None & 1 & 0 \\
\hline $\mathrm{OHA}$ & 22 & 24 \\
\hline Insulin & 1 & 4 \\
\hline $\mathrm{OHA}+$ insulin & 12 & 8 \\
\hline $\begin{array}{l}\text { Antihypertensive } \\
\text { medications }\end{array}$ & 23 & 21 \\
\hline Lipid-lowering medications & 12 & 15 \\
\hline \multicolumn{3}{|l|}{ Complications, no. } \\
\hline $\begin{array}{l}\text { Nonproliferative } \\
\text { retinopathy }\end{array}$ & 6 & 3 \\
\hline Microalbuminuria* & 9 & 5 \\
\hline Erectile dysfunction & 4 & 2 \\
\hline Neuropathy† & 6 & 5 \\
\hline Myocardial infarction $\ddagger$ & 2 & 6 \\
\hline Stroke & 1 & 1 \\
\hline Total no. of complications & 28 & 22 \\
\hline
\end{tabular}

Note: $\mathrm{SD}=$ standard deviation, $\mathrm{BMI}=$ body mass index, $\mathrm{BP}=$ blood pressure, $\mathrm{FPG}=$ fasting plasma glucose, $\mathrm{HbA}_{1 \mathrm{c}}=$ hemoglobin $\mathrm{A}_{1 \mathrm{C}}, \mathrm{LDL}-\mathrm{C}=$ low-density lipoprotein cholesterol, C:HDL-C = total cholesterol:high-density lipoprotein cholesterol, $\mathrm{OHA}=$ oral antihyperglycemic agents. *30-299 mg/L.

†Decreased sensation using a 10-g monofilament. ¥More than 1 year ago. 
was increased ( $0.32 \mathrm{U} / \mathrm{kg}$ per day); consequently, the dosage of glyburide was decreased by $4 \mathrm{I} \%$ in those taking insulin in the intervention group. Among patients in the intervention group taking oral antihyperglycemic agents only, dosages increased (by $34 \%$ for glyburide and by $22 \%$ for metformin), but the number of pills remained stable (Table 4). The number of patients receiving intensive multitherapy who required 3 or more antihypertensive agents tripled over time, and dosages increased by $30 \%$. Of 9 patients in the intervention group who were not taking antihypertensive medication at 12 months, 5 were at the target blood pressure at baseline and had remained there, and the other 4 had borderline blood pressure values (systolic blood pressure I34 [SD 3] $\mathrm{mm} \mathrm{Hg}$, diastolic blood pressure 77 [SD 9] $\mathrm{mm} \mathrm{Hg}$ ) and were reluctant to start treatment. Lipid-lowering medication was prescribed for $29 \mathrm{pa-}$ tients in the intervention group, and dosage increased by $50 \%$.
Of 5 patients in the intervention group with hypolipidemia, 4 reached low-density lipoprotein cholesterol and triglyceride targets with lifestyle changes only, and one patient, who refused hypolipidemic agents, did not achieve the targets.

No change was observed in the number or dosages of antihyperglycemic, antihypertensive or antihyperlipidemic prescriptions in the control group.

Overall, $42 \%$ of participants experienced at least one minor hypoglycemic episode per month. The mean number of episodes per month was similar in both groups (I.7 in the intervention group v. I.9 in the control group). In the intervention group, 3 severe hypoglycemic episodes (one concomitant with acute alcohol intoxication) were reported. Two nonlethal cardiac events were reported in each group.

Quality-of-life scores improved significantly in both groups (Table 2). However, this improvement was significantly greater

\begin{tabular}{|c|c|c|c|c|c|c|}
\hline \multirow[b]{2}{*}{ Variable, mean (SD) } & \multicolumn{3}{|c|}{ Intervention group; $n=34$} & \multicolumn{3}{|c|}{ Control group; $n=35$} \\
\hline & Baseline & $6 \mathrm{mo}$ & $12 \mathrm{mo}$ & Baseline & $6 \mathrm{mo}$ & $12 \mathrm{mo}$ \\
\hline \multicolumn{7}{|l|}{ Daily dietary intake } \\
\hline Energy, kcal & $2123(495)$ & $1913(392)$ & $1890(461)^{*}$ & $2003(688)$ & $1877(666)$ & $1835(531)$ \\
\hline Carbohydrates,g & $240 \quad(66)$ & $227 \quad(54)$ & $224 \quad(64)$ & 232 & 225 & $214 \quad(68)$ \\
\hline Fat, g & $88 \quad(23)$ & $75 \quad(22)$ & $71(19)^{*}$ & $79 \quad(32)$ & $74 \quad(33)$ & $70 \quad(26)$ \\
\hline Saturated fatty acids, g & $28 \quad(10)$ & $22 \quad(7)$ & $22(7)^{*}$ & $25 \quad(11)$ & $23 \quad(11)$ & $21(9)^{*}$ \\
\hline Cholesterol, mg & 370 (157) & 315 (137) & $310(140)^{*}$ & $299(140)$ & $295(142)$ & $291(104)$ \\
\hline \multicolumn{7}{|l|}{ Physical exercise } \\
\hline Exercise volume, METs & $7.53(9.28)$ & 18.99 (9.99) & $19.74(12.70)^{*} \dagger$ & $10.68(12.36)$ & $9.15(10.03)$ & $9.49(7.91)$ \\
\hline Exercise tolerance test, $\min$ & $5.42(2.18)$ & - & $6.24 \quad(2.30)^{*} \dagger$ & $5.24 \quad(2.00)$ & - & $5.36(2.24)$ \\
\hline Quality-of-life score $\neq$ & $67(12)$ & $75(11)^{*}$ & $75(11) \dagger$ & $71(11)$ & $72(10)$ & $74(12)^{*}$ \\
\hline
\end{tabular}

Note: $\mathrm{SD}=$ standard deviation, $\mathrm{MET}$ = metabolic equivalent tasks.

${ }^{*} p<0.05$ within group.

$t p<0.05$ change over time (baseline, 6, 12 months) between groups.

$\neq$ Score ranges from 0 to 100 , with 100 representing highest possible quality of life.

Table 3: CDA treatment goals attained at 12 and 18 months

\begin{tabular}{|c|c|c|c|c|c|c|}
\hline \multirow[b]{2}{*}{ Treatment goal } & \multicolumn{3}{|c|}{ Group; no. (\%) at $12 \mathrm{mo}$} & \multicolumn{3}{|c|}{ Group; no. (\%) at $18 \mathrm{mo}$} \\
\hline & $\begin{array}{c}\text { Intervention } \\
n=34\end{array}$ & $\begin{array}{c}\text { Control } \\
n=35\end{array}$ & $p$ value* & $\begin{array}{c}\text { Intervention } \\
n=32\end{array}$ & $\begin{array}{c}\text { Control } \\
n=29\end{array}$ & $p$ value* \\
\hline FPG $4.0-7.0 \mathrm{mmol} / \mathrm{L}$ & $14(41)$ & $7(20)$ & 0.056 & $8(26)$ & $6(21)$ & NS \\
\hline Hemoglobin $\mathrm{A}_{1 c}<7 \%$ & $12(35)$ & $3(8)$ & 0.007 & $3(9)$ & $2(7)$ & NS \\
\hline Systolic BP $<130 \mathrm{~mm} \mathrm{Hg}$ & $14(41)$ & $7(20)$ & 0.056 & $9(28)$ & $4(13)$ & NS \\
\hline Diastolic BP $<80 \mathrm{~mm} \mathrm{Hg}$ & $22(64)$ & $13(37)$ & 0.022 & $15(47)$ & $11(38)$ & NS \\
\hline $\begin{array}{l}\text { Low-density lipoprotein } \\
\text { cholesterol }<2.5 \mathrm{mmol} / \mathrm{L}\end{array}$ & $18(53)$ & $7(20)$ & 0.010 & $16(57)$ & $7(27)$ & 0.031 \\
\hline $\begin{array}{l}\text { Total cholesterol:high-density } \\
\text { lipoprotein cholesterol ratio } \\
<4.0\end{array}$ & $10(29)$ & $7(20)$ & 0.364 & $11(37)$ & $11(38)$ & NS \\
\hline Triglycerides $<1.5 \mathrm{mmol} / \mathrm{L}$ & $15(44)$ & $5(14)$ & 0.006 & $10(32)$ & $5(17)$ & NS \\
\hline
\end{tabular}

Note: $\mathrm{CDA}=$ Canadian Diabetes Association, $\mathrm{FPG}=$ fasting plasma glucose, $\mathrm{NS}=$ nonsignificant, $\mathrm{BP}=$ blood pressure

*Between-group comparisons were conducted with $\chi^{2}$ test. 

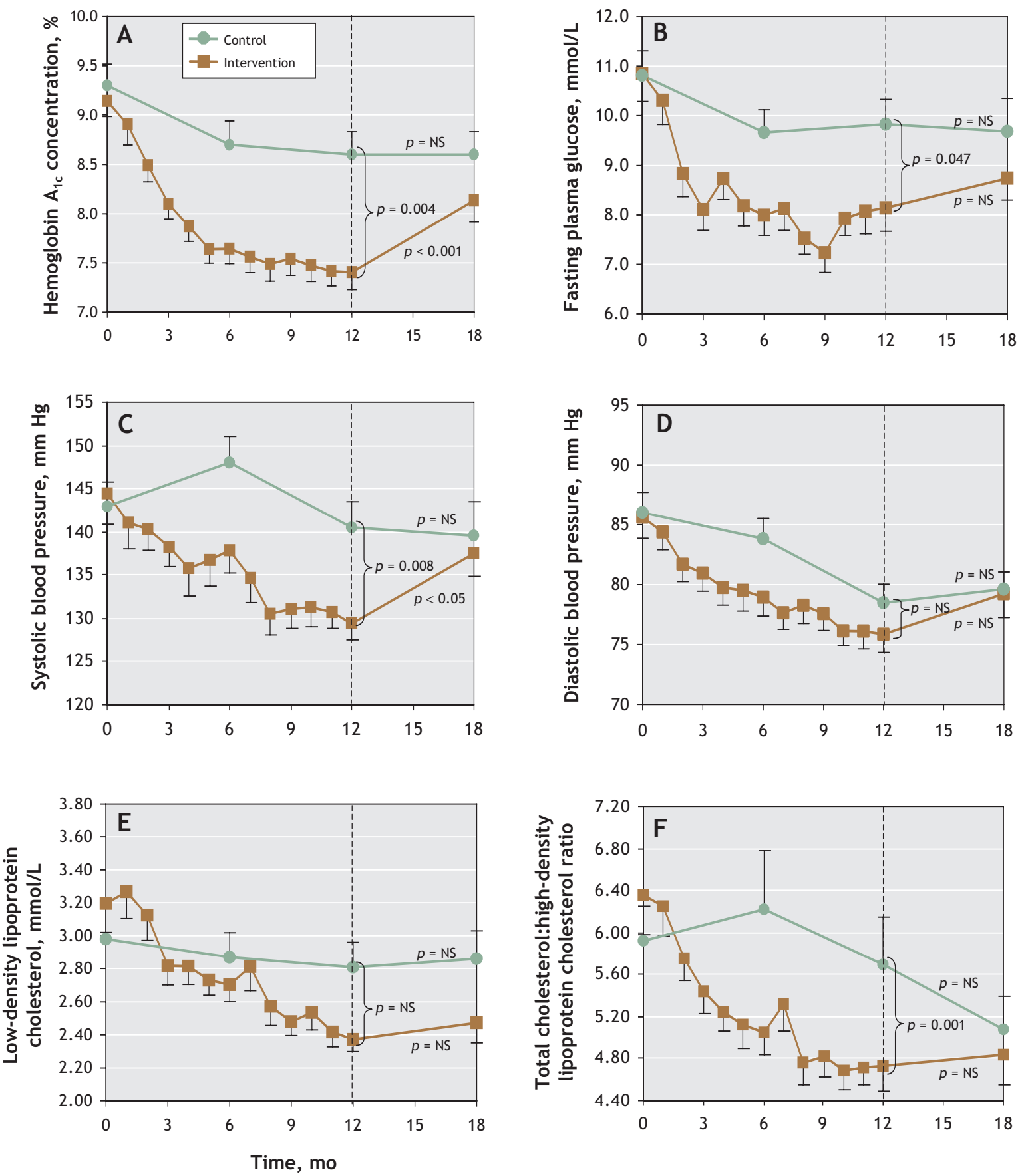

Fig. 2: Mean values for the treatment goals in the 2 study groups over the course of the study. A. Hemoglobin $A_{1 c}$ concentrations. B. Fasting plasma glucose. C. Systolic blood pressure. D. Diastolic blood pressure. E. Low-density lipoprotein cholesterol. F. Total cholesterol:high-density lipoprotein cholesterol. G. Trigyceride. The dots represent mean values, and the bars represent standard errors of the mean.

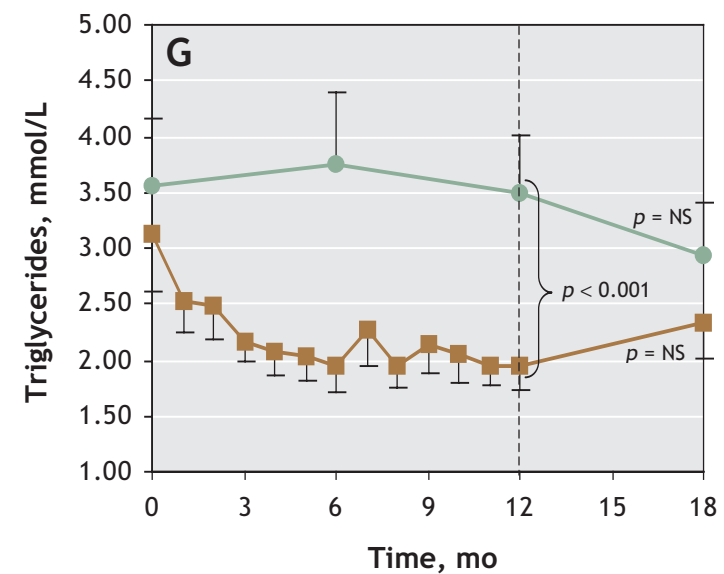


in the intervention group than in the control group ( $\mathrm{I} 3 \%$ [SD I0\%] v. $6 \%$ [SD I3\%]) over the 12 months $(p=0.003)$.

\section{At 18 months}

At I8 months, or 6 months after the intervention stopped, hemoglobin $\mathrm{A}_{\mathrm{rC}}$ concentrations, systolic blood pressure and body weight had increased significantly in the intervention group. Exercise volume had decreased in the intervention group (-I0.62 [SD I3.32] METs, $p<0.001$ ) and in the control group (-4.19 [SD 10.24] METs, $p=0.015)$, with no difference between the groups when decreases in exercise were expressed as percentages of 12 -month values. In the intervention group, time devoted to exercise had negative correlations with weight $(r=0.363, p=0.04 \mathrm{I})$ and with systolic blood pressure $(r=0.430, p=0.016)$. However, all outcome vari-

Table 4: Outcome variables and pharmacologic therapies at baseline and at 12 and 18 months

\begin{tabular}{|c|c|c|c|c|c|c|}
\hline \multirow[b]{2}{*}{ Variable, mean (SD)† } & \multicolumn{3}{|c|}{ Intervention group* } & \multicolumn{3}{|c|}{ Control group } \\
\hline & $\begin{array}{c}\text { Baseline } \\
n=34\end{array}$ & $\begin{array}{l}12 \mathrm{mo} \\
n=34\end{array}$ & $\begin{array}{l}18 \mathrm{mo} \\
n=32\end{array}$ & $\begin{array}{c}\text { Baseline } \\
n=35\end{array}$ & $\begin{array}{l}12 \mathrm{mo} \\
n=35\end{array}$ & $\begin{array}{l}18 \mathrm{mo} \\
n=29\end{array}$ \\
\hline \multicolumn{7}{|l|}{ Clinical } \\
\hline Weight, kg & $93.1(19.5)$ & $94.4(20.3)$ & $95.3(21.0) \S$ & $88.5(18.5)$ & $88.4(17.7)$ & $88.0(15.0)$ \\
\hline $\mathrm{BMI}, \mathrm{kg} / \mathrm{m}^{2}$ & $32.8(5.3)$ & $33.3(5.7)$ & $33.8(6.1) \S$ & $32.7(5.7)$ & $32.7(5.6)$ & $32.7(5.4)$ \\
\hline Systolic BP, mm Hg & $144(21)$ & 130 (12)§ף & 138 (15)‡ & $143(17)$ & $141(17)$ & $140(20)$ \\
\hline Diastolic BP, mm Hg & $85(11)$ & $76(9) \S$ & $79(11)$ & $86(10)$ & 78 (9)§ & $80(8)$ \\
\hline \multicolumn{7}{|l|}{ Biochemical } \\
\hline FPG, $\mathrm{mmol} / \mathrm{L}$ & $10.8(3.5)$ & $8.2(2.8) \S \rrbracket$ & $8.7(2.5)$ & $10.7(3.0)$ & $9.8(2.7)$ & $9.6(3.5)$ \\
\hline $\mathrm{HbA}_{1 c}, \%$ & $9.1(1.0)$ & $7.5(1.0) \S \rrbracket$ & $8.1(1.2) \S$ & $9.3(1.0)$ & $8.6(1.3) \ddagger$ & $8.6(1.3)$ \\
\hline LDL-C, mmol/L & $3.19(0.98)$ & $2.37(0.41) \S$ & $2.47(0.66)^{* *}$ & $2.98(1.18)$ & $2.81(0.79)$ & $2.86(0.86)$ \\
\hline C:HDL-C ratio & $6.35(2.16)$ & $4.73(1.43) \S \rrbracket$ & $4.84(1.60$ & $5.92(1.87)$ & $5.70(2.62)$ & $5.08(1.73)$ \\
\hline Triglycerides, \# mmol/L & $3.13(3.12)$ & $1.94(1.40) \neq 9$ & $2.33(1.76)$ & $3.55(2.39)$ & $3.50(3.05)$ & $2.93(2.44)$ \\
\hline \multicolumn{7}{|c|}{ Antihyperglycemic agents, no. (\%) } \\
\hline $1 \mathrm{OHA}$ & $13(38)$ & $13(38)$ & $14(44)^{* *}$ & $6(17)$ & $6(17)$ & $5(17)$ \\
\hline $2 \mathrm{OHA}$ & $16(47)$ & $18(53)$ & $16(50)$ & $24(69)$ & $24(69)$ & $21(72)$ \\
\hline $3 \mathrm{OHA}$ & $5(14)$ & $1(3)$ & $2(6)$ & $2(6)$ & $1(3)$ & $3(10)$ \\
\hline Insulin and $\mathrm{OHA}$ & $12(35)$ & $21(62) \ddagger^{* *}$ & $19(59)^{* *}$ & $8(23)$ & $10(29)$ & $10(34)$ \\
\hline Insulin alone & $1(3)$ & $2(6)$ & $3(9)$ & $4(11)$ & $4(11)$ & $4(14)$ \\
\hline $\begin{array}{l}\text { Insulin dose } \\
(\mathrm{U} / \mathrm{kg} \text { per } \mathrm{d}) \text {, no. (\%) }\end{array}$ & $0.47(0.26)$ & $0.79(0.43) \ddagger^{* *}$ & $0.79(0.49)^{* *}$ & $0.57(0.29)$ & $0.52(0.29)$ & $0.47(0.27)$ \\
\hline \multicolumn{7}{|c|}{ Antihypertensive agents, no. (\%) } \\
\hline 1 agent & $14(48)$ & $9(31)$ & $9(33)$ & $10(29)$ & $13(37)$ & $15(52)$ \\
\hline 2 agents & $6(21)$ & $6(21)$ & $5(19)$ & $9(26)$ & $7(20)$ & $3(10)$ \\
\hline$\geq 3$ agents & $3(16)$ & $10(35)$ & $10(37)$ & $2(6)$ & $5(14)$ & $6(21)$ \\
\hline \multicolumn{7}{|c|}{ Lipid-lowering agents, no. (\%) } \\
\hline Statin & $9(26)$ & $20(66) \ddagger^{* *}$ & $20(63)^{* *}$ & $8(23)$ & $7(20)$ & $5(17)$ \\
\hline Fibrate & $2(6)$ & $3(10)$ & $3(10)$ & $6(17)$ & $6(17)$ & $6(21)$ \\
\hline Both statin and fibrate & $1(3)$ & $6(20) \ddagger$ & $5(17)$ & $1(3)$ & $2(6)$ & $1(3)$ \\
\hline $\begin{array}{l}\text { Total no. of } \\
\text { pills/patient, mean (SD) }\end{array}$ & $6.3(3.6)$ & $6.8(3.4)$ & $6.5(3.4)$ & $6.0(3.0)$ & $6.5(3.2)$ & $6.4(3.6)$ \\
\hline
\end{tabular}

Note: $\mathrm{SD}=$ standard deviation, $\mathrm{BMI}=$ body mass index, $\mathrm{BP}=$ blood pressure, $\mathrm{FPG}=$ fasting plasma glucose, $\mathrm{HbA}_{1 \mathrm{c}}=\mathrm{hemoglobin}_{\mathrm{AC}}$,

$\mathrm{LDL}-\mathrm{C}=$ low-density lipoprotein cholesterol, $\mathrm{C}: \mathrm{HDL}-\mathrm{C}=$ total cholesterol:high-density lipoprotein cholesterol, OHA $=$ oral antihyperglycemic agents, ACE = angiotensin-converting enzyme.

*In the intervention group, 5 patients were and remained normotensive, and 4 patients achieved CDA lipid profile goals with lifestyle changes only.

†Unless stated otherwise.

Between-group comparisons of outcome variables were conducted using repeated-measurement analysis of covariance with baseline values used as covariates. Statistical differences are indicated as:

$\neq p<0.05$ within group.

$\S p<0.005$ within group

Ip $<0.05$ change over time (baseline and 6 and 12 months) between groups.

${ }^{* *} p<0.05$ comparison between groups at one particular time.

††Logarithmic transformation was applied to triglyceride values. 
ables remained significantly improved when compared with baseline $(p<0.03)$, with the exception of systolic blood pressure $(p=0.085)$.

Medication at I8 months was maintained from that at 12 months except for the dosage of statins in the intervention group, which had increased by $12 \%$, and sulfonylureas in the control group, which had increased by $25 \%$.

\section{Interpretation}

Using intensive and demanding therapy for type 2 diabetes over a I2-month period is feasible, and in our study it resulted in the attainment of most of the CDA-recommended goals. A higher proportion of intervention patients than control patients achieved goals for control of hemoglobin $\mathrm{A}_{\mathrm{IC}}$ concentrations, diastolic blood pressure, and low-density lipoprotein cholesterol and triglyceride levels. Intensive therapy is acceptable for patients with poorly controlled type 2 diabetes: no patient in the intervention group withdrew because of the therapy, and the quality-of-life scores were significantly improved at 12 months in that group compared with those of patients receiving usual care. However, 6 months after the intervention ended, there were no statistically significant differences in goal attainment between the study groups other than for low-density lipoprotein cholesterol levels.

Our study has some limitations. For ethical reasons, patients in the control group had protocol-driven laboratory tests, and they and their physicians received information about diabetes and its management as well as the results of these tests. Thus, control group patients may have received more aggressive treatment and attention than they normally would have. Similarly, patients receiving the intensive multitherapy may have been susceptible to the Hawthorne effect (people who know that performance is being measured perform with more care than they would normally). This may also have played a role in the improvements observed in the intervention group. ${ }^{23}$

Attainment of the CDA clinical practice goals was only partly achieved in the intervention group, and this effect did not continue after the end of intensive care. Our results are in accordance with those of the Steno-2 study, ${ }^{24}$ which showed limited achievement of the goals of the Danish Medical Asso-

Table 5: Dosages of oral medications by percentage of the maximum daily dosage* at baseline and at 12 and 18 months

\begin{tabular}{|c|c|c|c|c|c|c|}
\hline & \multicolumn{3}{|c|}{ Intervention group; \% (SD) } & \multicolumn{3}{|c|}{ Control group; \% (SD) } \\
\hline & Baseline & $12 \mathrm{mo}$ & $18 \mathrm{mo}$ & Baseline & $12 \mathrm{mo}$ & $18 \mathrm{mo}$ \\
\hline \multicolumn{7}{|l|}{ Glyburide } \\
\hline $\begin{array}{l}\text { In patients who started or } \\
\text { increased insulin }\end{array}$ & $\begin{array}{c}n=8 \\
74(34)\end{array}$ & $\begin{array}{c}n=11 \\
33(36) \dagger\end{array}$ & $\begin{array}{c}n=11 \\
32(36) \ddagger\end{array}$ & $\begin{array}{c}n=7 \\
64(28)\end{array}$ & $\begin{array}{c}n=7 \\
47(34)\end{array}$ & $\begin{array}{c}n=7 \\
72(25) \S\end{array}$ \\
\hline In patients taking $\mathrm{OHAs}$ only & $\begin{array}{l}n=15 \\
25(40)\end{array}$ & $\begin{array}{c}n=8 \\
59(37) 9\end{array}$ & $\begin{array}{c}n=8 \\
60(36) \ddagger\end{array}$ & $\begin{array}{l}n=21 \\
58(38)\end{array}$ & $\begin{array}{l}n=20 \\
67(31)\end{array}$ & $\begin{array}{l}n=18 \\
70(34)\end{array}$ \\
\hline \multicolumn{7}{|l|}{ Metformin } \\
\hline $\begin{array}{l}\text { In patients who started or } \\
\text { increased insulin }\end{array}$ & $\begin{array}{l}n=11 \\
66(27)\end{array}$ & $\begin{array}{l}n=19 \\
72(32)\end{array}$ & $\begin{array}{l}n=17 \\
83(18)\end{array}$ & $\begin{array}{c}n=8 \\
68(17)\end{array}$ & $\begin{array}{c}n=9 \\
82(14) 9\end{array}$ & $\begin{array}{c}n=7 \\
86(15)\end{array}$ \\
\hline In patients taking $\mathrm{OHAs}$ only & $\begin{array}{l}n=19 \\
61(37)\end{array}$ & $\begin{array}{c}n=11 \\
83(25) 9\end{array}$ & $\begin{array}{l}n=11 \\
83(25)\end{array}$ & $\begin{array}{l}n=22 \\
62(26)\end{array}$ & $\begin{array}{l}n=18 \\
67(29)\end{array}$ & $\begin{array}{l}n=18 \\
65(32)\end{array}$ \\
\hline Fibrate & $\begin{array}{c}n=3 \\
38(52)\end{array}$ & $\begin{array}{c}n=9 \\
100(0) \dagger\end{array}$ & $\begin{array}{c}n=8 \\
100(0) \ddagger\end{array}$ & $\begin{array}{c}n=7 \\
88(35)\end{array}$ & $\begin{array}{c}n=8 \\
100(0)\end{array}$ & $\begin{array}{c}n=7 \\
100(0)\end{array}$ \\
\hline Statin & $\begin{array}{l}n=10 \\
17(26)\end{array}$ & $\begin{array}{c}n=26 \\
53(30) \dagger\end{array}$ & $\begin{array}{c}n=25 \\
65(33) \neq \S\end{array}$ & $\begin{array}{c}n=9 \\
38(21)\end{array}$ & $\begin{array}{c}n=9 \\
33(21)\end{array}$ & $\begin{array}{c}n=6 \\
50(25)\end{array}$ \\
\hline $\begin{array}{l}\text { Angiotensin-converting enzyme } \\
\text { inhibitor }\end{array}$ & $\begin{array}{l}n=20 \\
37(23)\end{array}$ & $\begin{array}{l}n=16 \\
47(38)\end{array}$ & $\begin{array}{l}n=16 \\
59(30) \ddagger\end{array}$ & $\begin{array}{l}n=12 \\
22(27)\end{array}$ & $\begin{array}{c}n=18 \\
51(30) \dagger\end{array}$ & $\begin{array}{l}n=17 \\
47(28)\end{array}$ \\
\hline$\beta$-Blocker & $\begin{array}{c}n=2 \\
12(30)\end{array}$ & $\begin{array}{c}n=13 \\
70(33) \dagger\end{array}$ & $\begin{array}{c}n=12 \\
74 \text { (29)‡ }\end{array}$ & $\begin{array}{c}n=5 \\
40(44)\end{array}$ & $\begin{array}{c}n=8 \\
51(32)\end{array}$ & $\begin{array}{c}n=7 \\
55(33)\end{array}$ \\
\hline Calcium-channel antagonist & $\begin{array}{l}n=5 \\
69(37)\end{array}$ & $\begin{array}{c}n=5 \\
72(40)\end{array}$ & $\begin{array}{c}n=7 \\
76(25)\end{array}$ & $\begin{array}{c}n=7 \\
43(32)\end{array}$ & $\begin{array}{c}n=8 \\
60(28)\end{array}$ & $\begin{array}{c}n=6 \\
65(18)\end{array}$ \\
\hline $\begin{array}{l}\text { Angiotensin-II receptor } \\
\text { antagonist }\end{array}$ & $\begin{array}{c}n=1 \\
50\end{array}$ & $\begin{array}{c}n=7 \\
89(20) \dagger\end{array}$ & $\begin{array}{c}n=6 \\
92(20) \ddagger\end{array}$ & $\begin{array}{l}n=2 \\
50(0)\end{array}$ & $\begin{array}{c}n=1 \\
25\end{array}$ & $\begin{array}{c}n=1 \\
50\end{array}$ \\
\hline Diuretic & $\begin{array}{c}n=5 \\
29(36)\end{array}$ & $\begin{array}{c}n=9 \\
63(41) \dagger\end{array}$ & $\begin{array}{c}n=9 \\
56(38) \neq\end{array}$ & $\begin{array}{c}n=6 \\
38(33)\end{array}$ & $\begin{array}{c}n=7 \\
60(38)\end{array}$ & $\begin{array}{c}n=7 \\
64(35)\end{array}$ \\
\hline
\end{tabular}

Note: $\mathrm{SD}=$ standard deviation, $\mathrm{OHA}=$ oral antihypoglycemic agents.

*According to the 1998 Compendium of Pharmaceuticals and Specialties.

$\dagger p<0.05$ within group from 0 to 12 months.

$\neq p<0.05$ within group from 0 to 18 months.

$\S p<0.05$ within group from 12 to 18 months.

Ip $<0.10$ within group from 0 to 12 months. 
ciation. In day-to-day clinical practice, achieving the recommended goals may be even more difficult. Several reasons may explain these relatively disappointing results. First, in this study, the next target to reach was discussed at each visit, along with acceptance of a new medication and dosage by patients. This approach may explain why some medications were not prescribed and dosages not increased. Second, as well as patients' resistance to intensifying treatment, it is well-known that many physicians have concerns about treatment that is too aggressive. The fear of hypoglycemia for this patient population, the belief that even low or average levels of metabolic control can exert a positive effect and the idea that patients are unable to achieve recommended goals ${ }^{25,26}$ are strong components of practitioner behaviour. Although it is paradoxical in this experimental setting, we think that this behaviour, as well as the desire to retain patients in the trial, was present in the participating practitioners. However, the therapy given to the patients in our intensive multitherapy group was aggressive when compared with that described in a recent Canadian survey: ${ }^{27}$ among those with high blood pressure or dyslipidemia, $76 \%$ (v. $20 \%$ in the survey) were taking statins (plus 10\% who were taking fibrates) and $89 \%$ (v. $4 \mathrm{I} \%$ ) were prescribed angiotensin-converting enzyme inhibitors. It is important to point out that the intervention group and control group patients were taking the same number of pills; patients in the intervention group may have experienced better outcomes because dosages were more appropriate in this group.

Hypoglycemia and weight gain are major concerns in intensive treatment. In this study, the number of hypoglycemic episodes in the intervention group was comparable to those seen in studies in which comparable fasting plasma glucose levels and hemoglobin $\mathrm{A}_{\mathrm{rc}}$ concentrations were achieved. ${ }^{1,11}$ However, as in the Steno-2 study, ${ }^{11}$ we did not find a difference in the number of episodes between the 2 groups. More hypoglycemic episodes would have been recorded if lower hemoglobin $\mathrm{A}_{\mathrm{Ic}}$ concentrations had been reached. ${ }^{25}$ Body weight was stable over the $\mathrm{I} 2$-month intervention period, as was also observed in 2 earlier studies, ${ }^{1,11}$ even though many patients started or increased insulin therapy, which is usually associated with weight increase. ${ }^{28}$

At 6 months post-intervention, body weight, hemoglobin $\mathrm{A}_{\mathrm{rc}}$ concentrations and systolic blood pressure had increased significantly. This deterioration contrasts with the sustained quality-of-life scores achieved during the demanding multitherapy program. Thus it can be concluded that multitherapy is not detrimental to quality of life. The success of permanent lifestyle changes is dependent on patients' degree of motivation, psychosocial condition, risk profile and compliance: patient nonadherence to the lifestyle regimen is the most common barrier to care. ${ }^{29,30}$ Further studies are required to determine the best process for inducing long-lasting change in behaviour in type 2 diabetic patients. The Diabetes Control and Complications Trial, which studied intensive management of type I diabetes, also reported post-intervention worsening, but this occurred 4 years after the intervention. ${ }^{31}$ The rapid deterioration seen in our study seems to be related to a decrease in physical activity $(-50 \%)$ and probably in diet com- pliance, as suggested by the statistically significant increase in weight at 18 months and the negative correlations of exercise with weight and with systolic blood pressure. These results underline the importance of close follow-up organized around a multidisciplinary team that provides comprehensive and shared care. ${ }^{30,32,33}$ We may conclude that patients adhered to the program as long as they were being "coached."

Our intention was not to evaluate the contribution of each component of the intensive multitherapy management separately. Many other trials have focused on one or 2 interventions. ${ }^{34-37}$ We targeted lifestyle intervention through education and intense team-based follow-up, as is recommended in national association guidelines. ${ }^{15,16}$ In the absence of precise recommendations, we arbitrarily chose monthly follow-up, but the intensity and frequency of the monitoring should be evaluated in future studies.

Although intensive multitherapy is feasible and effective if maintained for 12 months, the benefits vanish rapidly when the patients resume usual care. The CDA treatment goals are very difficult to reach for patients with poorly controlled type 2 diabetes.

\section{This article has been peer reviewed.}

From the Diabetes and Metabolism Research Group (Ménard, Baillargeon, Maheux, Tessier, Ardilouze) and the Cardiology Unit, Clinical Research Centre (Lepage), Centre Hospitalier Universitaire de Sherbrooke, and the Research Centre on Aging (Payette, Tessier), Sherbrooke Geriatric University Institute, Sherbrooke, Qué.

\section{Competing interests: None declared.}

Contributors: Julie Ménard and Jean-Luc Ardilouze both contributed to the study concept, design and supervision; data acquisition, analysis and interpretation; and drafting of the manuscript; Julie Ménard also provided statistical expertise. Hélène Payette contributed to the study concept, design and supervision; data analysis and interpretation; and drafting of the manuscript, and provided statistical expertise. Jean-Patrice Baillargeon contributed to the study supervision and data acquisition, analysis and interpretation. Pierre Maheux contributed to the data acquisition, analysis and interpretation and provided statistical expertise. Serge Lepage contributed to data acquisition. Daniel Tessier contributed to data analysis and interpretation. All of the authors critically revised the manuscript for important intellectual content and gave final approval of the article to be published.

Acknowledgements: We thank Mireille Luc for analysis of the diet data. This work was supported by the Clinical Research Centre of the Centre Hospitalier Universitaire de Sherbrooke and by grants from Brystol-Myers Squibb and the Quebec Diabetes Association.

\section{REFERENCES}

I. UK Prospective Diabetes Study Group. Intensive blood-glucose control with sulphonylureas or insulin compared with conventional treatment and risk of complications in patients with type 2 diabetes: UKPDS 33 . Lancet $1998 ; 352: 837-53$

2. Stratton IM, Adler AI, Neil HA, et al. Association of glycaemia with macrovascular and microvascular complications of type 2 diabetes (UKPDS 35): prospective observational study. BMJ 2000;321:405-12.

3. UK Prospective Diabetes Study Group. Tight blood pressure control and risk of macrovascular and microvascular complications in type 2 diabetes: UKPDS 38 . $B M J 1998 ; 317: 703-13$.

4. Adler AI, Stratton IM, Neil HA, et al. Association of systolic blood pressure with macrovascular and microvascular complications of type 2 diabetes (UKPDS 36 ): prospective observational study. BMJ 2000;321:412-9.

5. Effects of ramipril on cardiovascular and microvascular outcomes in people with diabetes mellitus: results of the HOPE study and MICRO-HOPE substudy. Lancet 2000;355(9200):253-9. Erratum in: Lancet 2000;356(9232):86o.

6. Haffner SM, Alexander CM, Cook TJ, et al. Reduced coronary events in simvastatin-treated patients with coronary heart disease and diabetes or impaired fasting 
glucose levels: subgroup analyses in the Scandinavian Simvastatin Survival Study. Arch Intern Med I999;I59:266I-7.

7. Pyorala K, Pedersen TR, Kjekshus J, et al. Cholesterol lowering with simvastatin improves prognosis of diabetic patients with coronary heart disease. A subgroup analysis of the Scandinavian Simvastatin Survival Study (4S). Diabetes Care 1997; 20:614-20

8. Sacks FM, Pfeffer MA, Moye LA, et al. The effect of pravastatin on coronary events after myocardial infarction in patients with average cholesterol levels. Cholesterol and Recurrent Events Trial investigators. NEngI J Med 1996;335:100I-9.

9. Pollet RJ, El-Kebbi IM. The applicability and implications of the DCCT to NIDDM. Diabetes Review 1994;2:413-27.

Io. Cockcroft JR, Wilkinson IB, Yki-Jarvinen H. Multiple risk factor intervention in type 2 diabetes: an opportunity not to be missed. Diabetes Obes Metab 200I;3:I-8.

II. Gaede P, Vedel P, Parving HH, et al. Intensified multifactorial intervention in patients with type 2 diabetes mellitus and microalbuminuria: the Steno type 2 randomised study. Lancet 1999;353:617-22.

I2. Olivarius NF, Beck-Nielsen H, Andreasen AH, et al. Randomised controlled trial of structured personal care of type 2 diabetes mellitus. BMJ 2001;323:970-5.

I3. Hanefeld M, Fischer S, Schmechel H, et al. Diabetes Intervention Study: multi-intervention trial in newly diagnosed NIDDM. Diabetes Care I99I;I4:308-17.

I4. Joss N, Ferguson C, Brown C, et al. Intensified treatment of patients with type 2 diabetes mellitus and overt nephropathy. OJM 2004;97:219-27.

I5. Canadian Diabetes Association Clinical Practice Guidelines Expert Committee. Canadian Diabetes Association 2003 Clinical Practice Guidelines for the Prevention and Management of Diabetes in Canada. Can J Diabetes 2003;27(Suppl 2):Si-Si40.

I6. American Diabetes Association. 2005 Clinical Practice Recommendations. Dia betes Care 2005;28(Suppl I):SI-S79.

I7. The criteria committee of the New York Heart Association. Nomenclature and criteria for diagnosis of the diseases of the heart and great vessels. Boston: Little, Brown \& Co; 1994. p. 253-6.

I8. CANDAT. Nutrient Calculation System. 5.oth. London, Ont.: Godin London Inc. I997.

I9. Bruce RA. Exercise testing of patients with coronary heart disease. Principles and normal standards for evaluation. Ann Clin Res I971;3:323-32.

20. Pereira MA, FitzerGerald SJ, Gregg EW, et al. A collection of Physical Activity Questionnaires for health-related research. Med Sci Sports Exerc 1997;29(Suppl 6):SI53-6I.

2I. Kriska AM, Caspersen CJ. Introduction to a collection of physical activity questionnaires. Med Sci Sports Exerc 1997;29(Suppl 6):S5-9.

22. Fleiss JL. The design and analysis of clinical experiments. New York: John Wiley \& Sons, Inc; 1986.

23. Grufferman S. Complexity and the Hawthorne effect in community trials. Epidemiology I999;10:209-Io.

24. Gaede P, Vedel P, Parving $\mathrm{HH}$, et al. Multifactorial intervention and cardiovascular disease in patients with type 2 diabetes. N Engl J Med 2003;348:383-93.

25. Ross SA. Controlling diabetes: the need for intensive therapy and barriers in clinical management. Diabetes Res Clin Pract 2004;65(Suppl I):S29-34

26. Belfiglio M, De Berardis G, Franciosi M, et al. The relationship between physicians' self-reported target fasting blood glucose levels and metabolic control in type 2 diabetes: The QuED Study Group-Quality of care and outcomes in type 2 diabetes. Diabetes Care 200I;24:423-9.

27. Brown LC, Johnson JA, Majumdar SR, et al. Evidence of suboptimal management of cardiovascular risk in patients with type 2 diabetes mellitus and symptomatic atherosclerosis. $C M A J$ 2004;171:II89-92.

28. Yki-Jarvinen H. Combination therapies with insulin in type 2 diabetes. Diabetes Care 200I;24:758-67.

29. Dalewitz J, Khan N, Hershey CO. Barriers to control of blood glucose in diabetes mellitus. Am JMed Qual 2000;15:I6-25.

30. Gaede P, Beck M, Vedel P, et al. Limited impact of lifestyle education in patients with type 2 diabetes mellitus and microalbuminuria: results from a randomized intervention study. Diab Med 200I;18:104-8.
31. The Diabetes Control and Complications Trial/Epidemiology of Diabetes Interventions and Complications Research Group. Retinopathy and nephropathy in patients with type I diabetes four years after a trial of intensive therapy. $N$ Engl J Med 2000;342:38I-9.

32. Mensing C, Boucher J, Cypress M, et al. National standards for diabetes self-management education. Task Force to Review and Revise the National Standards for Diabetes Self-Management Education Programs. Diabetes Care 2000;23:682-9.

33. Wolpert HA, Anderson BJ. Metabolic control matters: why is the message lost in the translation? Diabetes Care 200I;24:130I-3.

34. Laitinen JH, Ahola IE, Sarkkinen IS, et al. Impact of intensive dietary therapy on energy and nutrient intakes and fatty acid composition of serum lipids in patients with recently diagnosed non-insulin-dependent diabetes mellitus. J Am Diet Assoc I993;93:276-83.

35. Franz MJ, Monk A, Barry B, et al. Effectiveness of medical nutrition therapy provided by dietitians in the management of non-insulin-dependent diabetes mellitus: a randomized, controlled clinical trial. JAm Diet Assoc 1995;95:1009-I7.

36. Lehmann R, Vokac A, Niedermann K, et al. Loss of abdominal fat and improvement of the cardiovascular risk profile by regular moderate exercise training in patients with NIDDM. Diabetologia 1995;38:1313-9.

37. Agurs-Collins TD, Kumanyika SK, Ten Have TR, et al. A randomized controlled trial of weight reduction and exercise for diabetes management in older AfricanAmerican subjects. Diabetes Care 1997;20:1503-II.

Correspondence to: Dr. Julie Ménard, Centre Hospitalier Universitaire de Sherbrooke, Clinical Research Centre, 300I I2th Ave. N., Sherbrooke QC $\mathrm{J}_{\mathrm{I}} \mathrm{H}_{5} \mathrm{~N}_{4}$, julie.menard@chus.qc.ca

\section{Editor's take}

- The Canadian Diabetes Association, along with other national associations, recommends specific targets for the metabolic control of diabetes. But are these guidelines and outcomes realistic?

- In this randomized controlled trial, frequent counselling regarding diet and weight loss; exercise, including provision of home exercise equipment; and aggressive management of diabetes, hypertension and hyperlipidemia over 12 months resulted in the attainment of at least some of the goals by between $20 \%$ and $64 \%$ of patients. Far fewer of the usualcare patients attained the CDA goals. Yet, 6 months after the study ended and multitherapy was discontinued, goal attainment in the intervention group had returned to levels similar to those of the control group.

Implications for practice: Physicians should expect few of their patients to attain the CDA goals and even fewer to maintain the goals over extended periods. 